\title{
ECOPEDAGOGIA E DIREITO AMBIENTAL
}

\author{
Eliane de Mello, Adriane da Silva Machado Möbbs
}

\section{RESUMO}

A efetivação do direito ambiental está estritamente relacionada com a Educação Ambiental formal e não formal crítica, alicerçada no paradigma da ecologia profunda, o que para alguns autores pode ser sintetizado no conceito de Ecopedagogia. Tal relação deve-se a compreensão de que o Direito Ambiental só poderá ser efetivado em uma sociedade formada por cidadãos que possuam uma visão complexa dos problemas ambientais e que fiscalizem a implementação de tais direitos. Neste contexto, um dos principais problemas seria a construção da cidadania, a qual, nas palavras de Edgar Morin, deveria ser uma "cidadania planetária".

\section{Palavras chaves: Cidadania, Ecopedagogia, Direito Ambiental;}

\section{Introdução}

Educação Ambiental e Direito Ambiental estão intimamente relacionados, pois para que haja a formulação de direitos ambientais realmente comprometidos com a proteção das pessoas e do planeta é necessário que o jurista tenha uma visão complexa da sociedade, o que requer uma grande mudança paradigmática na educação. Da mesma forma, para que esses direitos sejam realmente efetivados é preciso que a sociedade seja formada por cidadãos que fiscalizem a implementação de tais leis e que reivindiquem seus direitos.

Um exemplo da importância da participação cidadã na construção de políticas ambientais e na posterior formulação de leis foi a Eco-92, a qual consistiu em uma tentativa de reunir representantes de todos os países do mundo para discutir e divulgar a nova concepção de Desenvolvimento Sustentável que estava em voga, a partir da publicação do Relatório Brundtland. O principal documento resultante da Eco-92 foi a Agenda XXI, a qual apresentou um rol de programas que podem ser considerados instrumento fundamentais para a elaboração de políticas públicas em todos os níveis e que privilegiavam a iniciativa local (C.f. SOUSA, 2009). Tal evento, reuniu cidadãos de todo o mundo com o objetivo de discutir os problemas globais e procurar criar alternativas para os mesmos, pautados no entendimento de que a luta por direitos é fundamental neste contexto. Em outras palavras, sintetizou o conceito de cidadania que se espera para esta e as futuras gerações.

Destarte, o objetivo deste artigo é demonstrar que a Ecopedagogia pode ser uma proposta pedagógica capaz de contribuir para a efetivação do Direito Ambiental. 


\section{Metodologia}

A metodologia para realização desta pesquisa consistiu em pesquisas bibliográficas.

\section{A Ecopedagogia}

A Ecopedagogia nasceu da tradição latino-americana da educação popular, proposta por Paulo Freire e tem como objetivo a mudança nas relações humanas, sociais e ambientais da sociedade contemporânea (C.f. GADOTTI, 2000). De Freire advém a idéia da ética como essência do processo educativo e a compreensão deste como relação entre sujeitos que aprendem juntos a partir de relações dialógicas entre si e com a realidade.

A Natureza e as relações entre os seres humanos são tratadas pela Ecopedagogia, como um todo dinâmico, relacional, harmônico e auto-organizado em interação. Vê-se à Terra como um organismo vivo, seguindo a hipótese Gaia (C.f CAPRA, 1996). De forma geral, os referenciais teóricos que fundamentam o conceito de Ecopedagogia trazem uma composição de elementos do holismo, da complexidade e da pedagogia freireana (AVANZI, 2004).

O paradigma da complexidade, que engloba o holismo e, portanto traz aspectos do pensamento sistêmico, defendido por Frijof Capra (C.f CAPRA, 1996), se opõem ao modelo mecanicista de sociedade. O referido modelo colocava o conhecimento científico como verdade universal. Defendia que apenas a ciência poderia trazer o desenvolvimento às sociedades humanas e vinculava a idéia de progresso material ilimitado como forma de melhorar a vida das pessoas. O conhecimento era dividido em muitas partes, pois se acreditava que assim seria possível compreende-lo melhor, era o denominado conhecimento especializado. Eis algumas das principais características do pensamento linear (MENDONÇA, 2005, p. 117 -119):

- Necessidade de causa: Tudo precisa ter causa;

- Causalidade simples: Se dois fatos se repetem, estão muito próximos e um vem logo depois do outro, então o primeiro é a causa do segundo efeito;

- Coerência: Vigilância para que não haja contradição;

- Desvalorização do imaginário: Vê a realidade como algo concreto, "objetivo". Os efeitos precisam ser do mesmo contexto das causas;

- Monocordismo: Não aceita o uso de referenciais diferentes;

- Objetividade: Define a realidade como sendo formada por sujeitos e objetos separados entre si. Acredita que o sujeito/observador pode falar da realidade com imparcialidade, com isenção, sem deixar emergir a subjetividade;

- Quantificação: Valoriza prioritariamente as análises quantitativas. Exclui deliberadamente os aspectos humanos das situações/relações;

- Reatividade: Desconforto em relação ao novo. Prefere repetições;

- Seqüencialidade, ordem direta: Reage a tudo que esta fora da seqüência lógica e previsível das situações Reage a tudo que esta fora da seqüência lógica e previsível das situações; 
- Utilitarismo e imediatismo: Valoriza apenas aquilo que é útil, tem aplicação prática e imediata.

Para Mendonça, um dos efeitos do sistema linear foi a chamada "competição predatória", que compreende o desejo de eliminar completamente o adversário, levar as últimas conseqüências à agressividade, especialmente pela exclusão. Neste contexto, o prazer da vitória é associado à derrota do outro, característica que assumiu proporções planetárias no mundo moderno e contribuiu para a produção da desigualdade social, dos conflitos étnicos, dos racismos, dos machismos e da destruição ambiental (MENDONÇA, 2005, p. 117 - 119). Os antigos conceitos de virtudes - honestidade, humildade, tolerância, coragem, bom senso - foram e vão sendo descartados. Os valores que recebem destaque são aqueles que reproduzem o capitalismo, especialmente o consumismo. Para Morin, "no trânsito da modernidade e pós-modernidade produzimos a sociedade que nos produz" (MORIN, 2000, p. 23).

Ainda conforme o autor (C.f. MORIN, 1991), se no cartesianismo o todo é inferior à soma das partes, na complexidade o todo é, ao mesmo tempo, superior, inferior e diferente da soma das partes (VIÉGA, 2005). Assim, uma das observações mais destacadas para a educação ambiental é a de que é impossível explicarmos/compreendermos os problemas sócio-ambientais dentro do paradigma cartesiano (SANTOS, 2008). Daí a necessidade de haver uma grande mudança paradigmática na educação: de uma visão mecanicista, para uma visão complexa.

Deste modo, a Ecopedagogia se constrói como uma proposta pedagógica capaz de contribuir para a produção de uma visão complexa nos educandos, bem como favorecer a construção da cidadania através da resolução de problemas cotidianos. É concebida dentro de uma concepção freireana na qual a reflexão sobre a realidade é tida como possibilidade de buscar a compreensão dos problemas e consequentemente suas soluções. A ação transformadora sobre esta realidade é tida como um caminho para a emancipação do sujeito (C.f. BRANDAO, 1986). Para Paulo Freire, a educação é essencialmente um ato político que visa possibilitar ao educando a compreensão de seu papel no mundo e de sua inserção na história (C.f. FREIRE, 1987).

As críticas feitas pelos adeptos da Ecopedagogia à Educação Ambiental tradicional voltamse para as práticas que se fundamentam numa concepção de ambiente separadas das questões sociais. Do ponto de vista metodológico, há uma crítica a programas e projetos de ecologia e Educação Ambiental que se pautam por metodologias expositivas, enunciativas e impositivas com ênfase nos conteúdos.

A Planetaridade ou a cidadania planetária são expressões freqüentemente utilizadas na Ecopedagogia. A proposta é construir a participação cidadã, considerando nosso pertencimento ao planeta Terra como uma única comunidade, de modo que as diferenças culturais, geográficas, raciais e outras sejam superadas (C.f MORIN, 2001).

Para Moacir Gadotti, a cidadania planetária configurando-se a partir de novas territorialidades, que se apóiam no fortalecimento da perspectiva democrática de uma sociedade civil mundial em constituição a partir de uma ação política multiforme, conduzida em diversos níveis e com "novos métodos, novas soluções institucionais, financeiras, econômicas e sociais" (GADOTTI apud AVANZI, 2004). A transformação que se busca deve estar em consenso com as potencialidades do ser humano e as exigências da Terra, vista como organismo, dentro de uma concepção de sustentabilidade.

A Ecopedagogia enfatiza as interconexões entre os seres humanos, os fenômenos naturais e os sociais. Se o que se busca é uma profunda mudança de valores, relações, significações, 
entende-se que o processo pedagógico deve desenvolver atitudes de abertura, interação solidária, subjetividade coletiva, sensibilidade, afetividade e espiritualidade.

Francisco Gutiérrez e Daniel Pietro, propõem a pedagogia da demanda como uma proposta alternativa a concepção tradicional de educação. Para os autores, enquanto o discurso tradicional é lógico e estruturado em cima de verdades comprovadas cientificamente, o discurso da demanda é frágil, flexível, menos estruturado e processual, por estar situado nas circunstâncias que se apresentam na cotidianidade. Segundo Gutiérrez e Prado, a demanda como processo educativo apresenta-se em quatro dimensões: a) sócio-política: marcada pela democracia participativa; b) técnico-científica: que consiste na fundamentação do processo; c) pedagógica: que-fazer situado na cotidianidade; d) espaço-temporal: que considera a educação como um processo consumidor de tempo (GUTIÉRREZ E PIETRO apud AVANZI, 2004).

Conforme Avancini, a pedagogia da demanda pode ser considerada orientadora da prática ecopedagógica. Eis algumas chaves pedagógicas da proposta:

- Faz-se caminho ao andar: os caminhos devem ser construídos a partir de um fazer cotidiano e permanente;

- Caminhar com sentido: dar sentido ao que fazemos, impregnar de sentido as práticas da vida cotidiana e compreender o sem-sentido de muitas outras práticas;

- Caminhar em atitude de aprendizagem: desencadear processos pedagógicos abertos, dinâmicos, criativos, em que seus protagonistas estejam em atitude de aprendizagem permanente;

- Caminhar em diálogo com o entorno: a interlocução é tida como essência do ato educativo. Por interlocução, os autores compreendem "a capacidade de chegar ao outro, de abrir-se ao meio, de percorrer caminhos de compreensão e expressão, de promover processos e de facilitar aprendizagens abertas".

- No caminhar a intuição é prioritária: os sentimentos, a emotividade e a imaginação são considerados fundamento da relação entre os seres humanos e a natureza na perspectiva da Ecopedagogia;

- Caminhar como processo produtivo: é ressaltada a importância de resultados concretos para retroalimentar o processo educativo em construção. Trata-se de elaborar uma memória do processo de aprendizagem, a partir de registro escrito, gráfico, audiovisual do que se aprende a cada dia. Um registro que desempenhe o papel não de tarefas a serem cumpridas, mas como processo de busca de apreender a cotidianidade;

- Caminhar re-criando o mundo: em que se exercita a expressão criadora e a comunicação que, para os autores, geram compromisso, iniciativa, desinibição, auto-estima;

- Caminhar avaliando o processo: propõe-se um sistema de avaliação que permite integrar processos e produtos, em que se busque identificar: a apropriação de conteúdos, o desenvolvimento e mudança 
de atitudes, o desenvolvimento da criatividade, a capacidade de relacionar-se e expressar-se, a consecução de produtos que evidenciam o desenvolvimento pessoal. (GUTIÉRREZ E PIETRO apud AVANZI, 2004. p. 35-50).

Não se trata, portanto, de uma pedagogia meramente escolar, ainda que compreenda a escola como articuladora dos demais espaços educativos, mas sim de uma proposta que pretende alcançar os espaços de educação não formais da sociedade e que traz tal intenção como principio, pois compreende que a educação ambiental precisa estar disponível para toda sociedade.

Segundo Moacir Gadotti, o processo educativo desencadeado pela Ecopedagogia propõem a formação de um cidadão cooperativo e ativo, contrariamente ao que vem sendo desenvolvido pelas pedagogias tradicionais. $O$ que se busca é a constituição de sociedade sustentável "que não seja resultado de leis de mercado, mas da mudança de valores" (GADOTTI apud AVANZI, 2004. p. 35-50).

Para os adeptos da Ecopedagogia, esses valores e atitudes serão construídos a partir de um movimento pedagógico e sócio-histórico que forme cidadãos capazes de escolherem os indicadores de qualidade do seu futuro.

Nesta linha, os espaços formais de uma educação voltada para a complexidade e preocupada com as demandas da sociedade deveriam apresentar uma proposta pedagógica que contribua para a emancipação e autonomia, construção da cidadania, êxito e sucesso profissional, bem como, para a ética e a solidariedade. Para tanto, Rodrigues (2008) menciona alguns indicativos:

- as escolas deveriam tornar-se produtores efetivos de conhecimento teórico-prático e aptos a usá-los e disseminá-los de forma coerente e eficaz;

- os espaços educativos deveriam buscar a efetivação da autonomia frente às realidades contextuais de seus universos espaço-temporais;

- assumir funções educativas mais amplas, por si próprias ou através de interações com outras agências que tenham ou venham a ter caráter educativo;

- converter-se em espaços para a definição de políticas públicas, legitimando-se com isso no imaginário social e profissional e na dinamização cultural, social e, eventualmente, até mesmo econômica de seu entorno situacional;

- estimular a investigação, a pesquisa e a criatividade artística;

- elencar nos currículos saberes diferenciados, estimulando práticas pedagógicas mais humanas e éticas;

- estimular à produção de conhecimento vinculado a vida cotidiana, a fim de contribuir para diminuir as mazelas humanas;

- entender que o processo de formação docente e discente esta relacionado, tanto no plano coletivo como individual, as necessidades de conhecer para sobreviver;

- estimular a gestão democrática das escolas e dos processos de conhecimento, redefinindo as responsabilidades, formas de financiamento e competências de avaliar tais procedimentos; 
- promover discussões amplas e participativas, em fóruns específicos, que permitam analisar a qualidade da educação e a responsabilidade social da escola como agente de transformação e desenvolvimento humanos;

- estimular a participação dos alunos na construção dos currículos e projetos de pesquisa;

- promover a interdisciplinaridade, a transdisciplinaridade e a pesquisa;

- abrir os espaços de formação e diálogos com lideranças que auxiliem a superar os modelos e paradigmas mentais, culturais e pedagógicos vigentes, entendendo que o lidar com as situações novas exige o lidar com idéias e modos de ser novos, o que exige abertura, flexibilidade e aprendizado constante.

Destarte, a Ecopedagogia pode contribuir para a construção de uma visão complexa da sociedade. Esta visão será fundamental para que os sujeitos consigam lidar com os problemas contemporâneos, bem como preocupar-se com as gerações futuras. Outro aspecto fundamental da proposta é a construção da cidadania planetária. Como há uma compreensão de que os problemas são globais, os cidadãos precisarão se organizar globalmente, pois somente cidadãos organizados poderão exigir a promulgação de leis ambientais que realmente protejam os seres humanos e o planeta, bem como fiscalizar para que tais leis sejam cumpridas. Da mesma forma, destaca-se o fato de que é extremamente necessário que os juristas tenham uma visão complexa da sociedade, caso contrário, dificilmente produzirão leis que considerem as interligações existentes entre a natureza e toda sociedade, tanto desta geração, quanto das futuras. Em outras palavras, a Ecopedagogia esta intimamente relacionada com a efetivação do Direito Ambiental porque a educação, alicerçada no paradigma da complexidade é fundamental para a formação do jurista, mas também do cidadão que poderá exigir a efetivação de seus direitos.

\section{Resultados e discussões}

O processo educativo desencadeado pela Ecopedagogia propõem a formação de um cidadão cooperativo e ativo, contrariamente ao que vem sendo desenvolvido pelas pedagogias tradicionais. Para os adeptos da Ecopedagogia, esses valores e atitudes serão construídos a partir de um movimento pedagógico e sócio-histórico que forme cidadãos capazes de escolherem os indicadores de qualidade do seu futuro.

\section{Considerações finais}

Sabe-se que a crise ambiental é fruto de um modelo de desenvolvimento econômico não sustentável. Modificar este modelo implica na construção de uma nova forma de ver o mundo e de se relacionar com as pessoas e o meio ambiente. Neste contexto, um dos pressupostos básicos da educação ambiental é o de que esta deva colaborar para a construção da cidadania e na construção de uma visão complexa da sociedade, pois se entende que os problemas ambientais englobam problemas sociais, econômicos, culturais e políticos. 
No tocante ao sistema jurídico, é notório que não bastam somente leis rigorosas que penalizam o indivíduo infrator.

Assim, é desafio para a educação como um todo e, para a educação ambiental de modo especial, investigar formas de juntar o que foi separado (conhecimento), contribuir para que os homens e as mulheres estabeleçam relações mais justas, solidárias, participativas e democráticas, entre si e entre os demais seres vivos do planeta. Para tanto, a educação tradicional não serve. Como Paulo Freire, acreditamos que somente os cidadãos organizados poderão construir uma sociedade sustentável, resguardada pelo Direito Ambiental.

\section{REFERENCIAIS BIBLIOGRÁFICAS}

AVANZI, Maria Rita. Ecopedagogia. In: LAYTARGUES, P.P. (org). Identidades da educação ambiental brasileira. Brasília, MMA. Diretoria de Educação Ambiental, 2004. p. 35-50.

BRANDAO, C. R. Pesquisa participante. São Paulo. Brasiliense, 1986.

CAPRA, Fritjof. A teia da vida: uma nova compreensão científica dos sistemas vivos. São Pulo: Cultrix, 1996.

FREIRE, Paulo. Pedagogia do oprimido. Rio de Janeiro: Paz e Terra, 1987.

GADOTTI, Moacir. Pedagogia da Terra. São Paulo: Fundação Peirópolis, 2000.

MENDONÇA, Rita. Conserva e criar - Natureza, cultura e complexidade. São Paulo: Senac, 2005, p. $117-119$.

MORIN, Edgar. Introdução ao pensamento complexo. Lisboa: Instituto Piaget, 1991.

MORIN, Edgar. Os sete saberes necessários à educação do futuro. São Paulo: Cortez, 2001.

MORIN, Edgar. Para navegar no século XXI. Porto Alegre. Editora da PUCRS. 2000.

RODRIGUES, Zita Ana Lago. Paradigma da ciência, do saber e do conhecimento e educação para a complexidade: pressupostos e possibilidades para a formação docente . Educar, Curitiba, n. 32, p. 87-102, 2008.

SANTOS, Akiko. Complexidade e transdisciplinaridade em educação: cinco princípios para resgatar o elo perdido. Revista Brasileira de Educação v. 13 n. 37 jan./abr. 2008. Disponível em: < http://www.scielo.br>. Acesso em 12 fev. 2009.

SOUSA, Ana Cristina Augusto de. Evolução da política ambiental no Brasil do século XX. Disponível em: < http://www.achegas.net/numero/vinteeseis/ana sousa 26.htm>. Acesso em 6 de mai. de 2009.

VIÉGA, Aline. Complexidade: uma palavra com muitos sentidos. In: FERRARO-JUNIOR, L. A. (Coord.) Encontros e Caminhos: formação de educadoras(es) ambientais e coletivos educadores. Brasília: Ministério do Meio Ambiente, Diretoria de Educação Ambiental, 2005. p. 175- 187. Disponível em : <http://www.aja.org.br/publications/encontros.pdf>. Acesso em 11 fev. 2009. 